\title{
Retirement and cognitive development: are the retired really inactive?
}

Citation for published version (APA):

de Grip, A., Dupuy, A., Jolles, J., \& van Boxtel, M. P. (2012). Retirement and cognitive development: are the retired really inactive? METEOR, Maastricht University School of Business and Economics. METEOR Research Memorandum No. 009 https://doi.org/10.26481/umamet.2012009

Document status and date:

Published: 01/01/2012

DOI:

10.26481/umamet.2012009

Document Version:

Publisher's PDF, also known as Version of record

\section{Please check the document version of this publication:}

- A submitted manuscript is the version of the article upon submission and before peer-review. There can be important differences between the submitted version and the official published version of record.

People interested in the research are advised to contact the author for the final version of the publication, or visit the DOI to the publisher's website.

- The final author version and the galley proof are versions of the publication after peer review.

- The final published version features the final layout of the paper including the volume, issue and page numbers.

Link to publication

\footnotetext{
General rights rights.

- You may freely distribute the URL identifying the publication in the public portal. please follow below link for the End User Agreement:

www.umlib.nl/taverne-license

Take down policy

If you believe that this document breaches copyright please contact us at:

repository@maastrichtuniversity.nl

providing details and we will investigate your claim.
}

Copyright and moral rights for the publications made accessible in the public portal are retained by the authors and/or other copyright owners and it is a condition of accessing publications that users recognise and abide by the legal requirements associated with these

- Users may download and print one copy of any publication from the public portal for the purpose of private study or research.

- You may not further distribute the material or use it for any profit-making activity or commercial gain

If the publication is distributed under the terms of Article $25 \mathrm{fa}$ of the Dutch Copyright Act, indicated by the "Taverne" license above, 


\section{Maastricht University}

Andries de Grip, Arnaud Dupuy, Jelle Jolles, Martin van Boxtel

Retirement and cognitive development: are the retired really inactive?

RM/12/009

\section{METEOR}

Maastricht University School of Business and Economics

Maastricht Research School of Economics

of Technology and Organization

P. B. Box 616

NL -6200 MD Maastricht

The Netherlands 


\title{
Retirement and Cognitive Development: Are the Retired Really Inactive?*
}

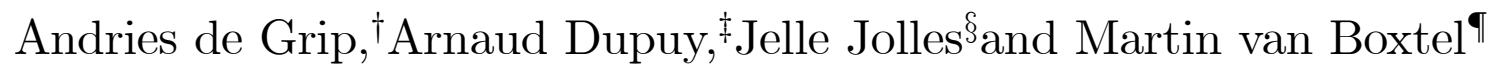 \\ February 14, 2012
}

\begin{abstract}
This paper uses longitudinal test data to analyze the relation between retirement and cognitive development. Controlling for individual fixed effects, we find that retirees face greater declines in information processing speed than those who remain employed. However, remarkably, their cognitive flexibility declines less, an effect that appears to be persistent 6 years after retirement. Both effects of retirement on cognitive development are comparable to those of a five to six-year age difference. They cannot be explained by (1) a relief effect after being employed in low-skilled jobs, (2) mood swings or (3) changes in lifestyle. Controlling for changes in blood pressure, which are negatively related to cognitive flexibility, we still find lower declines in cognitive flexibility for retirees. Since the decline in information processing speed after retirement holds particularly for the low educated, activating these persons after retirement could lower the social costs of an aging society.

JEL Classification: J24, J26.

Keywords: Cognitive decline, labor market activity, retirement.
\end{abstract}

*We acknowledge valuable comments from Eric Bonsang, Bart Golsteyn, Marike Knoef and participants at the International Pension Workshop 2012, Netspar.

$\dagger^{\dagger} \mathrm{ROA}$, Maastricht University, IZA and Netspar.

${ }^{\ddagger}$ ROA, Maastricht, IZA and Netspar. Corresponding address: Maastricht University PO Box 616, NL-6200, MD, The Netherlands. Email: a.dupuy@maastrichtuniversity.nl.

$\S$ Faculty of Psychology and Education, Free University of Amsterdam.

๑Department of Neuropsychology, Maastricht University 


\section{Introduction}

The graying of the post-war baby-boom generation and increased longevity are forcing European countries to postpone the mandatory retirement age to maintain the financial sustainability of the pension systems. Several studies in the economic literature analyze the physical and mental health of early versus later retirement (Dave et al., 2008; Coe and Zamarro 2011). Furthermore, there is an emerging literature on the effects of labor market inactivity on a person's cognitive abilities (see the survey by Skirbekk, 2008). While the psychological literature raises the related question of whether the non-use of cognitive abilities causes cognitive decline (Schaie, 1994, Bosma et al., 2003 ), it does not relate the use or non-use of cognitive abilities to participation in the labor market. This raises the question of whether a person at the edge of retirement has more cognitive stimuli at work or during retirement, which may mitigate the negative relation between cognitive capacity and age (Salthouse, 2006).

Both Bonsang et al. (2010) and Rohwedder and Willis (2009) find that retirement has a negative effect on cognitive functioning, whereas Coe and Zamorro (2010) do not find any effect, and Bingley and Martinello (2011) find a positive effect. Remarkably, these studies use the same or similar datasets and use country differences in the age pattern of retirement or retirement eligibility to control for unobserved heterogeneity and the endogeneity of retirement decisions. Bingley and Martinello criticize the instruments used by showing that different levels of average schooling across countries drive the negative correlation between retirement and cognitive functioning. Furthermore, all four studies focus merely on a person's memory as measured by a word recall test due to lack of alternative data. ${ }^{1}$ However, it should be noted that cognition refers to broad aspects of intellectual functioning and is essentially multidimensional (Bosma et al., 2003; De Grip et al., 2008).

This paper analyzes the effects of both the transition from work to retirement and being retired on the development of a person's cognitive abilities. We distinguish between four dimensions of cognition: 1) immediate and 2) delayed verbal memory, 3) cognitive flexibility (Stroop test), and 4) information processing speed and three types of labor market activity namely employed, inactive and retired. Our analyses use longitudinal information

\footnotetext{
${ }^{1}$ Bonsang et al. (2010) and Coe and Zamarro (2011) also include a verbal fluency score in their analyses.
} 
on workers' cognitive abilities from the MAastricht Aging Study (MAAS; Jolles, et al., 1995). We address the issue of causality using the panel structure of the data. In this data set, a person's cognitive abilities and labor market activity are measured at three points in time, wave 1 in 1993-1995; wave 2 in 1999-2001; wave 3 in 2005-2007. This allows us to measure the development of a person's cognitive abilities in two periods while controlling for individuals' fixed effects (in cognitive development) and lagged levels of cognition. ${ }^{2}$

The structure of these data allows us to distinguish between those who just retired and those who have been retired for at least 6 years. This allows us to differentiate between the short-term impact of the transition from work to retirement from the long-term impact of being retired. Since the psychological literature essentially explains the possible effects of labor market transitions from lifestyle-related changes in the use or non-use of a person's cognitive abilities, our analyses also include transitions between work and non retirement-related inactivity (unemployment or unpaid housework at an earlier age).

Remarkably, our fixed effects estimates show that those who retire face a significantly smaller decline in cognitive flexibility. This effect appears to be persistent since those who have been retired for six years or more also show a significantly lower decline in cognitive flexibility. The size of the effects is considerable and compares to the loss in cognitive flexibility between the ages of 65 and 70 to 71 years old. However, workers who retire face a significantly higher decline in information processing speed compared to those who remain at work. This reverse effect is of similar magnitude to the effect of retirement on cognitive flexibility. Following Coe and Zamorro (2011), we do not find a significant effect of retirement on (delayed) memory as Bonsang et al. (2010) and Rohwedder and Willis (2009) did. These results show that retirement may have different effects on the various dimensions of a person's cognitive ability.

We investigate the robustness of our findings by formulating three hypotheses that may mitigate the relationship between retirement and a person's cognitive development. The first hypothesis focuses on the possibly negative effect of continuous employment in an uninspiring job on a person's

\footnotetext{
${ }^{2}$ We use the bias-corrected Least Squares Dummy Variable (LSDV) estimator developed by Kiviet (1995) to account for the inherent downward bias in dynamic panel regression with fixed effects.
} 
cognitive development. From this hypothesis, we derive the expectation that, after a certain age, working has a wearing effect on certain cognitive abilities after someone has been doing the same routines for many years. Therefore low-skilled blue collar workers especially may benefit from this relief effect when they retire. We test this hypothesis by including an interaction term for the transition from work to retirement in white collar jobs in the analysis.

While the fixed effects allows us to control for potential bias due to unobserved variable/heterogeneity that changes at a constant rate over time, it is not robust for characteristics that change at different rates over time. We therefore formulate our second and third hypotheses, which further challenge the causal effect of retirement on cognitive decline by including changes in observed characteristics. The second hypothesis builds on the empirical neuropsychological literature, which finds evidence that a person's mood or mental health has a positive effect on cognitive development. Since mood changes are potentially positively related to cognitive development, the positive effect of retirement on cognitive flexibility could be due to a positive effect of retirement on a person's mood relative to continued labor market activity (see Esteban et al., 2007). Conversely, the negative effect of retirement on information processing speed may be explained by a negative effect of retirement on a person's mood. Since our data contains information on individuals' moods at three points in time, we test this hypothesis by including mood changes in the regression of cognitive development on activity status, and check the impact this inclusion has on the effect of retirement on cognitive decline.

The third hypothesis builds on empirical evidence found in the neuropsychological literature on the effect lifestyle can have on cognitive development (see Calero-García et al., 2007; and Fratiglioni et al., 2004). Since one expects individuals to change their lifestyle when they retire, the relation between retirement and a person's cognitive development could be due to the effect of retirement on lifestyle. Our data contain detailed information on the physical health of individuals and their drinking habits at the three points of measurement. These indicators for a person's lifestyle can be used to test our hypothesis by including changes in lifestyle characteristics in the regression of activity status on cognitive decline and checking the impact this has on the relation between retirement and cognitive decline.

Our estimation results show that neither the positive relation between retirement and a person's cognitive flexibility nor the negative relation between retirement and information processing speed are due to changes in a person's 
mood or lifestyle upon retirement. However, we find evidence that the negative relation between retirement and a person's information processing speed is only true for low-skilled persons.

Our paper contributes to three broader segments of the literature. First, it contributes to the literature on the obsolescence of human capital due to nonuse (see Rosen, 1975; Mincer and Ofek, 1982; De Grip et al., 2008) by gaining insight into the differences in the wear and tear effects of cognitive abilities during periods of labor market activity and inactivity. Second, we contribute to the literature on the costs and benefits of retirement and other kinds of labor market inactivity. Whereas increasing numbers of studies examine the mental health and unhappiness effects of unemployment (e.g.. Hamilton et al., 1997; Winkelmann and Winkelmann, 1998; Browning et al., 2006) on retirement (e.g. Lindeboom et al., 2002) only a few, as mentioned above, study the effects on a person's cognitive abilities. These studies, however, take into account only memory and do not specify a model that distinguishes between the change in cognitive abilities between only two measurements ${ }^{3}$ for workers who retire during this period and those who are retired at both measurements. Third, we contribute to the literature (e.g., Costa, 1998) on the social costs and benefits of postponing early and mandatory retirement.

The remainder of the paper is organized as follows. Section 2 discusses the data and the measures of cognitive ability, mood and lifestyle that we use in our analyses, including some descriptive statistics. Section 3 outlines our empirical methodology and reports on the estimation results. Section 4 tests the three alternative hypotheses in mitigating the effect of retirement on cognitive decline. Section 5 concludes the paper.

\section{Data}

Our analyses use the data of the Maastricht Aging Study (MAAS) (for a full account of this study's setting, we refer the reader to Jolles et al., 1995). The MAAS aims at drawing a better understanding of the determinants of cognitive aging. Its participants were recruited from the Registration Network of Family Practices ( Metsemakers et al., 1992), a database containing information about 80,000 persons registered at 57 general family doctors'

\footnotetext{
${ }^{3}$ Pooled OLS and fixed effects regressions of the level of cognition on retirement show a positive and often significant coefficient. The results are available from the authors upon request.
} 
practices $^{4}$ in the region of South Limburg, in the Netherlands. This population was pre-screened and about $4 \%$ were excluded because of chronic neurological pathology (e.g., evidence of strokes, epilepsy or dementia), mental retardation, or chronic psychotropic drug use. The remaining population was stratified into 13 age classes, and about 850 patients by age class (about 11,000 patients in total) were randomly drawn from that population and sent an invitation to participate in the study. Another $5 \%$ of this group was excluded from the study by their practitioner during a visit in the practice for chronical pathologies. About 8,000 patients invited to take part in the study completed the postal questionnaire containing information about demographic variables, biological life events, general health and life, and psychological health. Of this group, about 4,500 (60\%) patients volunteered for the additional test program, that took place in a hospital and consisted of a medical and neurocognitive assessment.

About 2,800 participants were randomly drawn from the pool of 4,800 volunteers, to participate in the MAAS study. The participants were stratified by age (with 12 age categories) and gender. The final data set $^{5}$ contains baseline measurement data on 1,800 healthy participants, aged between 24 and 81 years old at baseline measurement in 1993-1995, say, time $T$. The same persons were then retested twice with the same test battery: once after six years (i.e., in the period 1999-2001), at $T+6$, and once after 12 years (i.e., in the period 2005-2007), at $T+12$. The attrition rate is about $25 \%$ (435 participants dropped out) between $T$ and $T+6$, and $13 \%$ between $T+6$ and $T+12$ (another180participants). Fortunately, the probability of dropping out between two waves is not related to labor market activity or cognitive measures (in levels between $T$ and $T+6$ and levels and change between $T+6$ and $T+12$ ), except for information processing, for which there is some evidence that those who dropped out had experienced a decline in that measure between the first two measurements. ${ }^{6}$

\footnotetext{
${ }^{4}$ In the Netherlands, every individual is registered at a family doctor.

${ }^{5}$ About 600 were excluded after the first telephone contact either because their status was incompatible with the testing -for instance, 100 used daily psychoactive medication and 20 had very poor visual and auditory function - or because they were aged outside of the limits for the study. Another 330 declared not to be interested in the program after the first telephone contact and 90 simply did not show up at the first meeting.

${ }^{6}$ These results are derived from a (probit) regression of the attrition status (dummy equals one if a participant dropped out of the study between two waves) on the labor market activity, levels and changes (for the attrition between the last two waves) in our four measures of cognition and age and education. Detailed results are available from the
} 
Using the three waves of cognition measurement, we construct two "waves" of measurement of cognitive development. The first wave contains information about cognitive decline between $T$ and $T+6$, and the second wave contains information about cognitive development between $T+6$ and $T+12$. These constructed data comprise a two-period unbalanced panel of about 1,360 individuals. On average, individuals were observed 1.8 times.

These data enable us to distinguish between three different labor market statuses: employed, retired, and (other) inactive. The "retired" category encompasses early retirement and retirement defined as people aged 65 (i.e., the mandatory retirement age) or older who do not have paid work. Those who are neither employed nor retired are classified as inactive. From the "useit-or-lose-it" perspective, note that being retired or inactive merely refers to labor market status and not necessarily the level of intellectual or physical activity since the inactive group includes those involved in voluntary work.

$<$ Insert Table 1 $>$

As indicated by the transition matrices between $t$ and $t+6$, with $t=$ $T, T+6$, reported in Table 1, a non-negligible number of persons changed their employment status in the two periods we distinguished. In both periods about $20 \%$ change their employment status. This means that we have sufficient observations off the diagonal to distinguish between, for instance, persons inactive at both $t$ and $t+6$ from those inactive at $t$ but employed at $t+6$. The remainder of the paper distinguishes between six groups: those inactive at both $t$ and $t+6$ (group $I I$ ), those inactive at $t$ and employed at $t+6$ (group $I A$ ), those retired at both $t$ and $t+6$ (group $R R$ ), those employed at $t$ and inactive at $t+6$ (group $E I$ ), those employed at $t$ and retired at $t+6$ (group $E R$ ), and the reference group $(E E)$ ), consisting of those employed both at $t$ and $t+6$.

\subsection{Cognitive abilities}

In the three test periods, $T, T+6$ and $T+12$, respondents underwent the same set of standard neuropsychological tests to assess the following cognitive domains:

- Memory, as in immediate recall (Word Learning Task or WLT test),

authors upon request. 
- Memory, as in delayed recall (WLT test),

- Cognitive flexibility (Stroop test), an

- Information processing speed (Letter Digit Substitution Test or LDST).

The WLT evaluates the ability to acquire and retain new verbal information (Van der Elst, et al., 2005). In each of three trials, a set of 15 frequently used monosyllabic words were presented in a fixed order at a rate of one every two seconds. These tests enable us to measure two aspects of a person's cognitive abilities: their immediate recall abilities and their delayed recall abilities. After every trial, the participant had to reproduce the memorized words (immediate recall test). The total number of correctly reproduced words in three trials was recorded. Twenty minutes after the last trial, the participant was again asked to reproduce the set of words (delayed recall test) and the number of correctly reproduced words was recorded.

Selective attention and susceptibility to perceptual interference was measured by the Stroop Color and Word Test (Stroop, 1935; Van der Elst et al., 2006b) which indicates a person's cognitive flexibility. The test involves naming as quickly as possible the colors of the printing ink of 100 names of colors that do not match the color of the ink with which they are printed. The number of seconds to complete the task is recorded. Performance in this test is determined largely by the time needed to discard irrelevant but very salient information (verbal) in favor of a less obvious aspect (the printing ink color). It should be noted that a higher score (i.e., more seconds) on this test indicates lower cognitive ability.

Finally, we used the LDST, a paper-and-pencil task in which a person is asked to copy as accurately and as quickly as possible the numbers in a series of boxes that are indexed by a unique letter. The letters refer to nine letternumber combinations displayed in a table at the top of the test sheet. The number of correctly copied numbers after 90 seconds is used as the measure of interest (Van der Elst et al., 2006a). In neuropsychological assessment, this test is often used to obtain a general measure of information processing speed (Lezak, 2004).

It is important to note that since employment status (retirement) is correlated with age, one needs to carefully isolate changes in cognition due to age from changes due to other causes (e.g., changes in employment status). As Figures 1 and 2 suggest, the age-profiles of cognition and cognitive decline 
can be accurately approximated by low-order polynomials, for instance the quadratic form.

$<$ Insert Figures 1 and 2>

$<$ Insert Table $2>$

Table 2 shows the average mean levels and standard deviations of the variables for our six groups. It shows that those who remained employed between $t$ and $t+6$ had higher cognitive abilities than those who remained inactive or retired. Moreover, those who retired (i.e., changed from being employed to being retired) between $t$ and $t+6$ also had lower cognitive abilities than those who remained employed. However, these differences are largely due to the large difference in average age between the two groups.

$<$ Insert Table $3>$

As Table 3 shows, those who remained employed did not show greater development (i.e., $\operatorname{Cog}_{i t+6}-\operatorname{Cog}_{i t}$ ) in all four cognitive abilities than those who remain inactive or retired between the two test periods. In addition, the cognitive development of employed persons who retire between the two test periods was not systematically worse than for those who remained employed.

\subsection{Mood}

Our test of alternative explanations for the relation between cognitive decline and retirement when measuring cognition by information processing or cognitive flexibility uses the data available on the respondents' mood. To measure mood, we use the respondents' responses to mood-related questions that ask the respondents to express the extent to which they agree with 16 statements related to their mood (cf. Wallace and Herzog, 1995). The following is a subset of four of these statements.

On a scale from 1 (absolutely not) to 5 (totally), to what extent does the following apply to you?

- I blame myself for everything happening to me.

- I feel lonely.

- I am at the far end of my rope. 
- I am irritable.

Principal component analysis on the 16 statements reveals that the answer to the third statement above, "I am at the far end of my rope," correlates very strongly, at about 0.85 , with the first two principal components that together explain about $50 \%$ of the total variance. Since missing values are relatively frequent and scattered across statements, we limited the number of missing values by using the answer to this particular statement as a proxy for mood, rather than the sum of the answers to all 16 statements. We construct our measure of mood by subtracting the answer to the statement from zero such that a higher score indicates a better mood. Table 3 shows that both those who remain retired and those who retire between the two test periods show a relative improvement in their mood compared to those who remain employed.

\section{$2.3 \quad$ Lifestyle}

To test our third hypothesis on the effect of differences in life style on cognitive development, we use data available on the physical health and drinking behavior of the respondents. Since we are interested in physical health changes related to life styles, changes in Body Mass Index $\left(\Delta B M I_{t+6}\right)$ and blood pressure, ${ }^{7}\left(\Delta B P_{t-t+6}\right)$, seem to be the most appropriate variables. Moreover, we use the available data on changes in drinking behavior as proxied by the average number of glasses of alcohol per day $\left(\Delta D \operatorname{Drink}_{t+6}\right)$. However, of the 1,360 respondents selected, we only obtained information on alcohol use for about 990 persons in the three waves. Table 3 shows that the physical health of those who remained retired as well as those who retired between the two test periods improved relative to those who remained employed. This holds for all four measures we included in our analysis.

\footnotetext{
${ }^{7}$ The dataset also includes a measure of auditive functioning, but this measure (in levels or changes) is not correlateed with labor market activity or our measures of cognition.
} 


\section{Empirical methodology and results}

\subsection{Main model}

This paper analyzes the impact of labor market status on cognitive decline, which we define as change in cognition between two waves. The model we estimate is:

$$
\begin{aligned}
\operatorname{Cog}_{i t+6}-\operatorname{Cog}_{i t}= & X_{i t}^{\prime} \beta+Z_{i}^{\prime} \alpha+\alpha \operatorname{Cog}_{i t}+E R_{i t} \delta_{E R}+R R_{i t} \delta_{R R}+ \\
& I I_{i t} \delta_{I R}+I E_{i t} \delta_{I E}+E I_{i t} \delta_{E I}+ \\
& \tau_{t}+\varepsilon_{i t}^{\prime}
\end{aligned}
$$

where $X_{i t}^{\prime}$ contains covariates that vary over time, age, and age squared, ${ }^{8} Z_{i}$ contains covariates that are constant over time such as gender, eight educational dummies and eight occupational dummies. $I I_{i t}$ takes the value one if person $i$ was inactive at $t$ and $t+6$ and zero otherwise, $I E_{t i}$ takes the value one if person $i$ was inactive at $t$ and employed at $t+6$ and zero otherwise, $R R_{i t}$ takes the value one if person $i$ was retired at $t$ and retired at $t+6$ and zero otherwise, $E I_{i t}$ takes the value one if person $i$ was employed at $t$ and inactive at $t+6$ and zero otherwise and $E R_{i t}$ takes the value one if person $i$ was inactive at $t$ and retired at $t+6$ and zero otherwise. $\tau_{t}$ a period-specific fixed effect. Furthermore, we relate change in cognition to a person's level of cognition at $t$. This enables us to take into account the fact that the absolute loss of cognition may be higher for those with higher levels of cognition at the beginning of the period.

We begin the analysis by estimating the model depicted in Equation 1 ignoring the panel structure of the data and applying OLS to the pooled crosssection for our four measures of cognition, respectively the WLT, delayed WLT, Stroop and LDST separately. As noted, a higher score indicates higher cognitive abilities for all tests but the Stroop, where a high score (i.e., more seconds) indicates lower cognitive abilities.

$<$ Insert Table $4>$

\footnotetext{
${ }^{8}$ Higher orders are rarely significant and as suggested by Figures 1 and 2, the quadratic form is sufficient to pick up the age profile in cognitive decline.
} 
Table 4 shows that those who are inactive in the labor market do not face a higher cognitive decline than those who are employed. However, the results clearly show a significantly lower cognitive decline for those who were retired at both $t$ and $t+6$ compared to people working at both $t$ and $t+6$, for all four measures of cognition. Moreover, we find that those who retire between $t$ and $t+6$ experienced a lower decline in their cognitive flexibility than those who remained employed. Furthermore, our estimation results show that, for all four measures, cognitive decline was greater in absolute terms for those with higher cognition at the beginning of the period as indicated by the negative and significant coefficients for initial cognition.

Next we estimate the model using fixed effects. The effect of variables contained in $Z_{i}$, fixed over time, are now captured as part of the individual fixed effects $\mu_{i}$ :

$$
\begin{aligned}
\operatorname{Cog}_{i t+6}-\operatorname{Cog}_{i t}= & X_{i t}^{\prime} \beta+\alpha \operatorname{Cog}_{i t}+E R_{i t} \delta_{E R}+R R_{i t} \delta_{R R}+ \\
& I I_{i t} \delta_{I R}+I E_{i t} \delta_{I E}+E I_{i t} \delta_{E I}+ \\
& \tau_{t}+\mu_{i}+\varepsilon_{i t}^{\prime}
\end{aligned}
$$

As is well known in the literature (Nickell, 1981), the slope coefficients in this model are downward biased when using Least Dummy Variable Estimator (LSDV). To correct for this bias, we apply Kiviet's (1995) bias-corrected LSDV estimator (LSDVC), and in particular use the Stata routine xtlsdvc developed by Bruno (2005).

It is important to note that our specification in Equation 2 is dynamic. The identifying assumption of our fixed effects model requires the effect of unobserved variables on changes in cognition to be constant over time. This identifying assumption is weaker than that required in a static fixed effects model: The effect of unobserved variables on the level of cognition is constant over time.

The results are reported in Table 5 . With respect to information processing (LDST), cognitive decline is larger and significant for those who retired between $t$ and $t+6$ compared to those who continued working, while with respect to cognitive flexibility (Stroop test) the cognitive decline is still lower and significant. This finding reveals a causal effect of retirement on cognitive decline with a different direction for different dimensions of cognition. The magnitude of these effects is considerable, resembling the difference in cognition between the age of 65 and 70 years old. 


\section{$<$ Insert Table 5>}

Furthermore, we have experimented with various age specifications such as selecting only respondents aged 50 and above at baseline or adding a cubic term. In all these specifications we found coefficients for $E R$ and $R R$ of a similar magnitude as those presented in this paper. While the coefficients are still significant for the cubic specification, selecting only those aged 50 or more at baseline requires dropping $60 \%$ of our respondents, which subsequently increased the confidence intervals of our estimates and made our coefficients become insignificant.

\subsection{Measurement errors and the learning effect}

As is well known in the psychological literature, cognitive tests suffer from a learning effect; that is, at constant cognitive ability, people will perform better at a test they have already done in the past. The learning effect could be seen as a specific change in measurement errors from period to period. Including a period fixed effect allows us to control for the general impact of the learning effect. It is important to note that in all specifications, the period fixed effect (with the second period as the reference) is positive (although not significant in the fixed effect model), indicating a lower cognitive decline in the first period.

One may argue, however, that measurement errors are systematic and drive the strong negative effect of retirement on cognitive decline. Suppose that cognition is measured with errors and write $C o g^{*}=C o g+e r r$ where $\mathrm{Cog}$ is the real cognition, $\mathrm{Cog}^{*}$ is the measured cognition, and the err are measurement errors. Suppose that the errors of measurement systematically differ across employment groups and especially between retired people and the rest. A possible reason for this could be that retired people are more motivated to do well in the test, are less stressed, or have more time to prepare, such that they have better test results than those with the same cognitive abilities but who are still employed. In this case, it is conceivable that for retired persons measured cognition is equal to true cognition $\operatorname{Cog}^{*}=$ Cog, while for employed persons measured cognition is below true cognition, $\mathrm{Cog}^{*}<C o g$ or err $<0$. However, since we are interested in changes in cognition, this systematic measurement error is not enough to be the cause of the lower cognitive decline for retired people observed above. If the errors are the same all three times that people take the test, then the cognitive decline is 
not contaminated by measurement errors. Hence, these measurement errors can only affect differences in cognitive decline between employed and retired persons when the test effort of retired persons increases between $T$ and $T+6$ and between $T+6$ and $T+12$ compared to the test efforts of those who remain employed. Although theoretically possible, the change in the "motivation" of retired people relative to the employed that is required to fit with the above coefficient is implausible: $\Delta \operatorname{Cog}_{i R}^{*}-\Delta \operatorname{Cog}_{E E}^{*}=\Delta \operatorname{Cog}_{i R}-\Delta \operatorname{Cog}_{E E}+$ $\Delta e r r_{i R}-\Delta e r r_{E E}=\Delta e r r_{i R}-\Delta e r r_{E E}=\delta_{i R}$ for $i=E, R$. Retired people, for instance, need to increase their motivation for the Stroop test compared to employed persons to increase their cognition by six to seven points compared to those employed.

As mentioned above, the magnitudes of our estimates correspond to the loss of cognition a person experiences between the ages of 65 and 70 years. This casts serious doubts on the plausibility of measurement errors as the driving force behind the lower decline in cognitive flexibility we found for retired persons. In addition, a higher test effort of the retired is not in line with the greater decline in their information processing speed.

\section{Test of alternative hypotheses}

\subsection{Cognitive declines in low-skilled work and among the low skilled}

The lower cognitive decline of retired persons could be due to the fact that working after a certain age has a wearing effect on cognitive ability. This "relief effect" can especially occur in low-skilled jobs where workers repeat the same routines for years. To test this hypothesis, we check whether the effect of retirement on cognitive decline is linked to the type of job prior to retirement. For this purpose, we augment our regression with the interaction of retirement $E R$ with a person's job level. Herewith, we distinguish between white and blue collar occupations. The estimation results, presented in Table 6 , show that the interaction term for being retired after having worked in a white collar job is not significantly related to declines in information processing or cognitive flexibility. The estimation results show that greater cognitive decline in terms of cognitive flexibility and lower cognitive decline in terms of information processing for elderly persons who are still employed compared to retired workers in the same age cohort is unrelated to job content before 
retirement.

$<$ Insert Table $6>$

Next, we run similar regressions where we interact retirement and workers' level of education, focusing on the dichotomy between high and low-skilled persons. The results reported in Table 7 show that the higher cognitive decline of elderly persons who are still employed compared to that of retired workers in the same age cohort is unrelated to their level of education for cognitive flexibility. However, we find evidence that higher-educated retirees face a significantly lower decline in their information processing speed (as measured by the LDST) when retired than when still employed. This suggests that it is the low educated who suffer from a decline in information processing speed upon retirement.

$<$ Insert Table $7>$

\subsection{Do mood and life-style changes explain the lower cognitive decline of retirees?}

Since mood and life-style have been recognized as major determinants of cognitive decline, retirement may cause a lower decline in cognitive flexibility when retirees improve their mood compared to persons who remain employed, or when their lifestyle is more favorable to cognitive development than that of those who continue working. Conversely, the higher decline in information processing speed for those who retire from work may be explained by a worse mood or lifestyle for retirees. We test for the effect of mood and lifestyle by alternatively adding mood changes and lifestyle changes to Equation 2.

We estimate Equation 3, which augments Equation 2 with changes in $W_{i t+6}$ between $t$ and $t+6$ where $W$ is either mood or a measure of lifestyle:

$$
\begin{aligned}
\Delta \operatorname{Cog}_{i t+6}= & X_{i t+6}^{\prime} \beta+\alpha \operatorname{Cog}_{i t}+E R_{i t} \delta_{E R}+R R_{i t} \delta_{R R}+ \\
& I I_{i t} \delta_{I I}+I E_{i t} \delta_{I E}+E I_{i t} \delta_{E I}+ \\
& \Delta W_{i t+6} \gamma+\tau_{t}+\mu_{i}+\varepsilon_{i t+6}^{\prime}
\end{aligned}
$$

If the variable $W$ is responsible for the effect of retirement on cognitive decline, with $\Delta W_{i t+6}$ in the regression, the coefficient for mood or lifestyle, $\gamma$, should be significant and, at the same time, the coefficients for $\delta_{R R}$ and $\delta_{E R}$ should drop and become insignificant. 


\subsubsection{Results}

The results, reported in Table 8, show that mood changes are not significantly associated with any of our four dimensions of cognitive decline. This indicates that neither the positive impact of retirement on cognitive flexibility nor the negative impact on information processing speed is due to differences in mood between retirees and those who remain employed.

\section{$<$ Insert Table $8>$}

We use four indicators to proxy for respondents' lifestyles. The first two indicators reflect changes in lifestyle concerning a person's physical health, namely, changes in (1) BMI, $\left(\Delta B M I_{t-t+6}\right)$, and (2) blood pressure, $\left(\Delta B P_{t-t+6}\right)$. The last life-style variable reflects respondents' drinking behavior, namely the change in (3) the average number of glasses of alcohol per day, $\left(\Delta G \operatorname{Drink}_{t-t+6}\right)$. The results, reported in Tables 9 and 11, show that changes in BMI and daily alcohol consumption are not related to cognitive development. Moreover, the effects of retirement on cognitive development $\left(\delta_{E R}\right.$ and $\left.\delta_{R R}\right)$, do not drop. We conclude that the relation between cognitive development and retirement cannot be attributed to changes in BMI or alcohol consumption. A similar conclusion can be derived for changes in blood pressure, except for cognitive flexibility, as indicated in Table 10. Indeed, the results show that those who experience an increase in blood pressure also have to cope with a significantly stronger decline in their cognitive flexibility (i.e., a higher score on the Stroop test). Nevertheless, this effect does not alter the relation between the decline in cognitive flexibility and retirement; that is, the coefficients are of similar magnitude as in the previous specifications and become even significant at the $5 \%$ level, as shown in Table 10 .

$<$ Insert Table 9>

$<$ Insert Table 10 and 11>

\subsubsection{Preferred specifications}

To summarize our main findings, Table 12 presents the main coefficients of interest for our preferred specification. For memory and delayed memory, we find no effects of retirement or labor market inactivity on cognitive decline (even when controlling for the role of skills) or any relation between mood 
and life-style on the one hand, and cognitive decline, on the other. Our preferred specification is therefore the fixed effects regression presented in Equation 2. In contrast, for cognitive flexibility, we find that changes in blood pressure have a significant negative impact on cognitive development, and our preferred specification is the fixed effects regression including changes in blood pressure. For the information processing measure, we find that none of the life-style variables have an impact on cognitive development. However, the negative impact of retirement on information processing speed seems to be relevant only for low-skilled persons. Our preferred specification is therefore the fixed effects regression including the interaction of the employed retired dummy with the educational level dummy.

$<$ Insert Table $12>$

Since the scale of the cognitive tests is hard to interpret, the magnitude of our estimates is better expressed in terms of life years, making use of the relation between age and cognition. Using the estimates of Table 12, we find that a 65-year-old worker has the cognition flexibility of a 69.5-year-old retired person. On the other hand, a 65-year-old low-skilled retired person has the information processing cognition of a 71-year-old low-skilled worker.

\section{Conclusion and implications}

This paper uses longitudinal test data to analyze the effect of retirement on a person's cognitive abilities with respect to memory, cognitive flexibility, and information processing speed. Our data allow us to distinguish between the effects of the transition from work to retirement on a person's cognitive development and the persistence of these effects after being retired for a longer period. Controlling for individual fixed effects, we find that those who retire from work face greater declines with respect to information processing speed than those who remain employed. However, remarkably, those who retire face less decline with respect to their cognitive flexibility. Moreover, this effect appears to be persistent after being retired for at least six years. The effects we find are comparable to the effect of a five-year age difference and cannot be explained by (1) measurement errors, (2) a relief effect after being employed in low-skilled jobs, (3) mood swings, or (4) positive changes in lifestyle upon retirement. Controlling for changes in blood pressure, which are negatively related to cognitive flexibility, the lower decline in cognitive 
flexibility for the retirees still holds. However, since our proxies for a person's lifestyle only pick up the effects of lifestyle related to physical health, we can only conclude that differences in lifestyle that may affect cognitive decline are not related to physical health or drinking habits. The same holds for mental health, in-so-far as this is measured by our mood indicator. Our data do not allow us to analyze whether the lower decline in cognitive flexibility of retirees is related to being involved in more intellectual activities (Erickson et al., 1986), social relationships (Cohen, 2004), or a more varied lifestyle (volunteer activities, traveling, etc.) after retirement (Siegrist et al., 2004).

The contrasting results we find for information processing and cognitive flexibility suggest a trade-off between various aspects of cognition: Participating in activities that develop one aspect of cognition (cognitive flexibility) may reduce the development of other aspects (information processing). This resembles the findings of a recent study by Woollett and Maguire (2011), who show that experienced qualified London taxi drivers display a greater memory for spatial knowledge but lesser memory for the delayed recall of complex figures compared to less experienced or retired taxi drivers or control participants. Our findings suggest that this trade-off holds particularly for low-educated retirees.

Our estimation results do not support the "use-it-or-lose-it" findings of Bonsang et al (2010) and Rohwedder and Willis (2009) with respect to persons' recall abilities. However, with respect to these memory abilities our findings resemble those of Coe and Zamarro (2011). The different results on the development of a person's memory after retirement between our study and those of Bonsang et al. and Rohwedder and Willis may also be related to the different settings in which cognition was tested. Whereas the memory cognition tests in the HRS and SHARE were part of the survey interview, the MAAS participants were tested in a hospital setting. We expect this hospital setting improved the testing commitment of all participants.

The positive effect we find of retirement on a person's cognitive flexibility shows that retirement does not necessarily refer to the non-use of a person's cognitive abilities. Retirees may, for instance, enrich their lives through voluntary activities, travel, and other challenging activities that broaden their scope compared to the narrower range of activities at work before retirement. From this perspective, it is understandable that this finding particularly holds for a person's cognitive flexibility. When persons retire, they have to learn new routines and may get involved in a much broader range of new activities than they were involved in at the end of their working careers. It is interest- 
ing to see that this does not hold for those who become inactive at a younger age because of unemployment or other causes of labour market inactivity.

Obviously, our findings may have important policy implications. To cope with the increasing costs of an aging population, in many industrialized countries public policy aims to postpone the mandatory age of retirement. Our results suggest that this postponement of retirement has a positive effect on the information processing speed of the elderly but accelerates the decline of their cognitive flexibility, which may increase both the social and financial costs of an aging population. Since the decline in information processing speed after retirement is especially true for the low-educated, activating such persons after retirement could lower the social costs of an aging society.

\section{References}

Bingley, P., And A. Martinello (2011): "Retirement Improves Cognitive Performance," mimeo.

Bonsang, Eric, S. A., And S. Perelman (2010): "Does retirement affect cognitive performance?," ROA research memorandum 2010/1.

Bosma, H., M. Van Boxtel, R. Ponds, P. Houx, A. Burdorf, and J. Jolles (2003): "Mental Work Demands Protect Against Cognitive Impairment: MAAS Prospective Cohort Study.," Experimental Aging Research, 29, 33-45.

Browning, M., A. Moller Dano, and E. Heinesen (2006): "Job displacement and stress-related health outcomes," Health Economics, 15(10), 1061-1075.

Bruno, G. S. (2005): "Approximating the bias of the LSDV estimator for dynamic unbalanced panel data models," Economics Letters, 87(3), 361366.

Calero-Garcia, M., E. Navarro-Gonzalez, and L. Munoz-Manz (2008): "Influence of Level of Activity on Cognitive Performance and Cognitive Plasticity in Elderly Persons," Archives of Gerontology and Geriatrics, forthcoming. 
Calvo, E., K. Haverstick, and S. A. Sass (2007): "What Makes Retirees Happier: A Gradual or 'Cold Turkey' Retirement?," Working Papers, Center for Retirement Research at Boston College wp2007-18, Center for Retirement Research.

Coe, N., H.-M. von Gaudecker, M. Lindeboom, and J. Maurer (2010): "The Effect of Retirement on Cognitive Functioning," mimeo.

Coe, N. B., and G. Zamarro (2011): "Retirement effects on health in Europe," Journal of Health Economics, 30(1), 77-86.

Cohen, S. (2004): "Social Relationship and Health," American Psychologist, 59(8), 676-684.

Costa, D. L. (1998): "The Evolution of Retirement: Summary of a Research Project," The American Economic Review, 88(2), 232-236.

Dave, D., R. I. S. J. (2008): "The effects of retirement on physical and mental health outcomes.," Southern Economic Journal, 75, 497-523.

De Grip, A., H. Bosma, D. Willems, and M. Van Boxtel (2008): "Job-Worker Mismatch and Cognitive Decline," Oxford Economic Papers, forthcoming.

Erickson, Erik H., E. J. M., And H. Q. Kivnick (1986): Vital Involvement in Old Age. New York, NY: Norton.

Fratiglioni, L., S. Paillard-Borg, and B. Winblad (2004): "An Active and Socially Integrated Lifestyle in Late Life Might Protect Against Dementia," The Lancet Neurology, 3, 343-353.

Hamilton, V., P. Merrigan, and E. Dufresne (1997): "Down and Out: Estimating the Relationship Between Mental Health and Unemployment," Health economics, 6, 397-406.

Jolles, J., P. Houx, M. Van Boxtel, and R. W. H. M. Ponds (1995): Maastricht Aging Study: Determinants of Cognitive Aging. Neuropsych Publishers.

LeZAK, M. D. (2004): Neuropsychological Assessment. New York: Oxford University Press. 
Lindeboom, M., F. Portrait, and G. Van Den Berg (2002): "An Econometric Analysis of the Mental-Health Effects of Major Events in the Life of Older Individuals," Health Economics, 11(6), 505-20.

Metsemakers, J. F. M., P. Hoppener, J. Knottnerus, R. J. J. Kocken, and C. B. G. Limonard (1992): "Computerized Health Information in the Netherlands: A Registration Network of Family Practices.," British Journal of General Practice, 42, 102-106.

Mincer, J., A. O. H. (1982): "Interrupted Work Careers: Depreciation and Restoration of Human Capital," Journal of Human Resources, 17, 3-24.

Rohwedder, S., And R. J. Willis (2009): "Mental Retirement," Netspar discussion paper 10/2009-03\%.

Rosen, S. (1975): "Measuring the Obsolescence of Knowledge," in Education, Income and Human Behavior, ed. by F. T. Juster, pp. 199-232. New York: Carnegie Foundation for the Advancement of Teaching and National Bureau of Economic Research.

Salthouse, T. (2006): "Mental exercise and mental aging: Evaluating the validity of the Şuse it or lose it $\breve{T}$ hypothesis.," Perspectives on Psychological Science, 1, 68-87.

Schaie, K. (1994): "The Course of Adult Intellectual Development.," American Psychologist, 49, 304-313.

Siegrist, J., O. Von Dem Knesebeck, and C. E. Pollack (2004): "Social Productivity and Well-Being of Older People: A Sociological Exploration," Social Theory and Health, 2(1), 1-17.

Stroop, J. R. (1935): "Studies of Interference in Serial Verbal Reactions," Journal of Experimental Psychology, 18, 643-662.

Van Berkel, A. B., and B. Tax (1990): "Naar Een Standaardoperationalisatie Van Sociaal-Economische Status Voor Epidemiologisch En Sociaal-Medisch Onderzoek [Towards a Standard Operationalization of Socio-Economical Status for Epidemiological and Socio-Economical Research]," Den Haag: Ministerie van Welzijn, Volksgezondheid en Cultuur. 
Van der Elst, W., M. P. Van Boxtel, G. J. Van Breukelen, and J. Jolles (2006a): "The Stroop Color-Word Test: Influence of Age, Sex, and Education; and Normative Data for a Large Sample Across the Adult Age Range," Assessment, 13, 62-79.

Van der Elst, W., M. P. J. Van Boxtel, G. J. P. Van Breukelen, AND J. Jolles (2005): "Rey's Verbal Learning Test: Normative Data for 1,855 Healthy Participants Aged 24-81 Years and the Influence of Age, Sex, Education, and Mode of Presentation," Journal of the International Neuropsychological Society, 11, 290-302.

(2006b): "The Letter Digit Substitution Test: Normative Data for 1,858 Healthy Participants Aged 24-81 from the Maastricht Aging Study (MAAS): Influence of Age, Education, and Sex," Journal of Clinical and Experimental Neuropsychology, 28, 998-1009.

Wallace, R. B., and A. R. Herzog (1995): "Overview of the Health Measures in the Health and Retirement Study," The Journal of Human Resources, 30, S84-S107.

Winkelmann, L., and R. Winkelmann (1998): "Why Are the Unemployed So Unhappy? Evidence from Panel Data," Economica, 65, 1-15.

Woollett, K., And E. A. Maguire (2011): "Acquiring Şthe KnowledgeT of londonŠs Layout Drives Structural Brain Changes," Current Biology, 21, 2109-2114. 
WLT
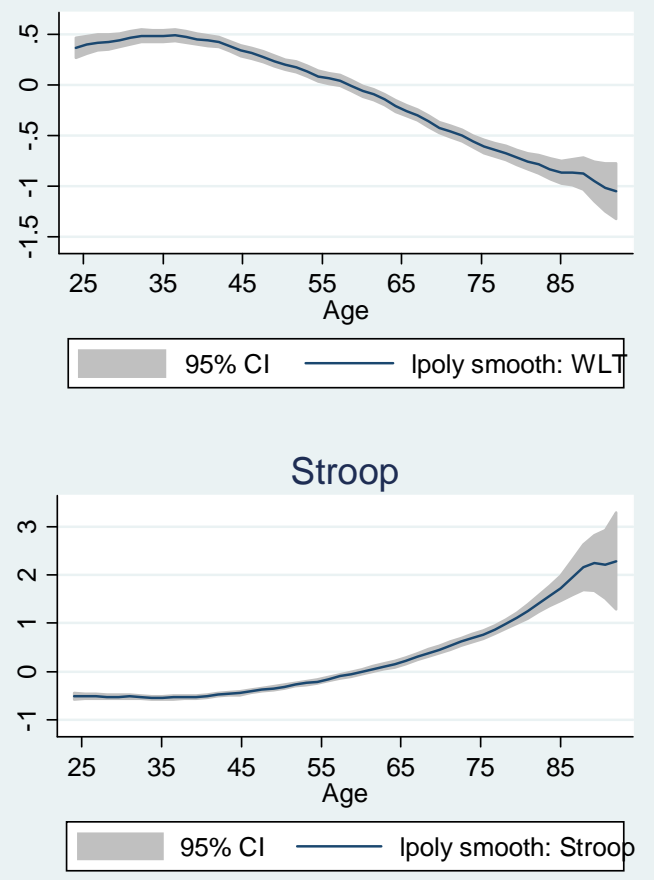

WLT delay

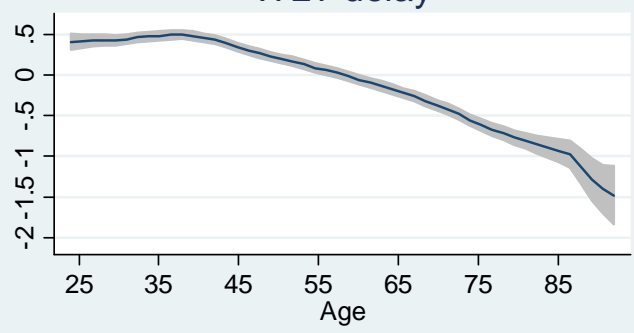

$95 \% \mathrm{Cl} \longrightarrow$ Ipoly smooth: WLTdel

LDST

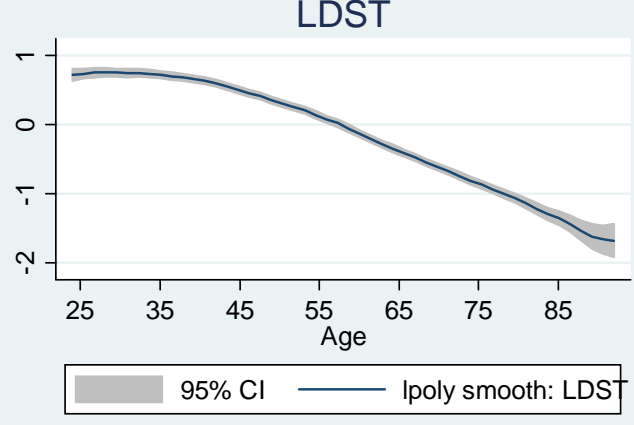

Figure 1: Cognition scores and age. Local polynomial smoothing and $95 \%$ confidence interval of the z-score by age. 

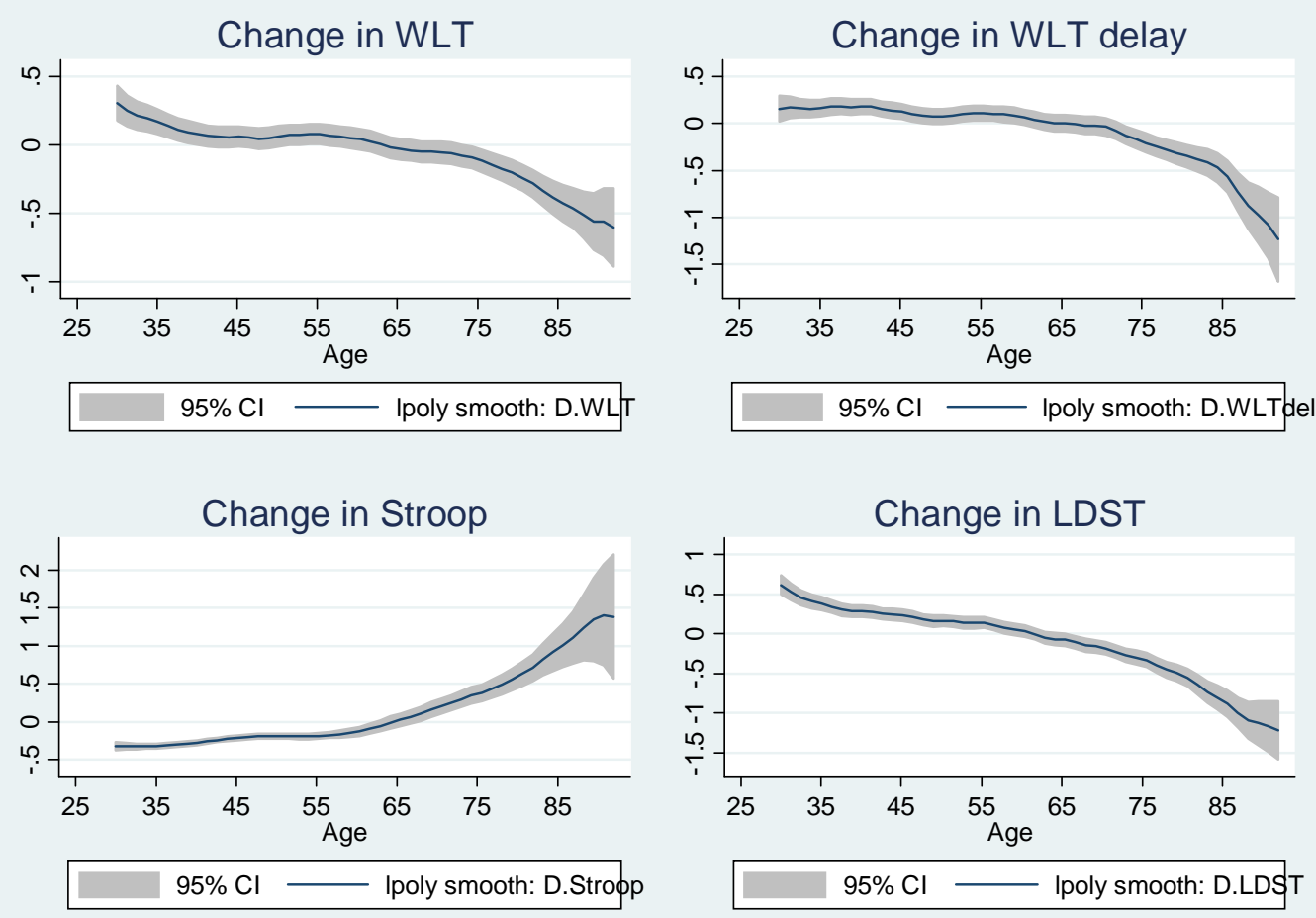

Figure 2: Change in cognitive scores and age. Local polynomial smoothing and $95 \%$ confidence interval of the z-score by age. 
Table 1: Employment status transition matrix between $\mathrm{t}$ and $\mathrm{t}+6$.

\begin{tabular}{lccccc}
\hline \hline & & & Activity at T+6 & & \\
& & Inactive & Retired & Employed & Total \\
& Inactive & 22.2 & 0 & 4.8 & 27.0 \\
Activity at $T$ & Retired & 0 & 19.6 & 0 & 19.6 \\
& Employed & 5.3 & 3.5 & 45.6 & 54.4 \\
& Total & 27.5 & 23.1 & 50.4 & 100 \\
\hline \hline \multirow{5}{*}{ Activity at $T+6$} & & Activity at T+12 & & \\
& & Inactive & Retired & Employed & Total \\
& Inactive & 17.9 & 0 & 8.5 & 26.4 \\
& Retired & 0 & 23.7 & 0 & 23.7 \\
& Employed & 5.0 & 7.0 & 37.9 & 49.9 \\
& Total & 22.9 & 30.7 & 46.4 & 100 \\
\hline \hline
\end{tabular}




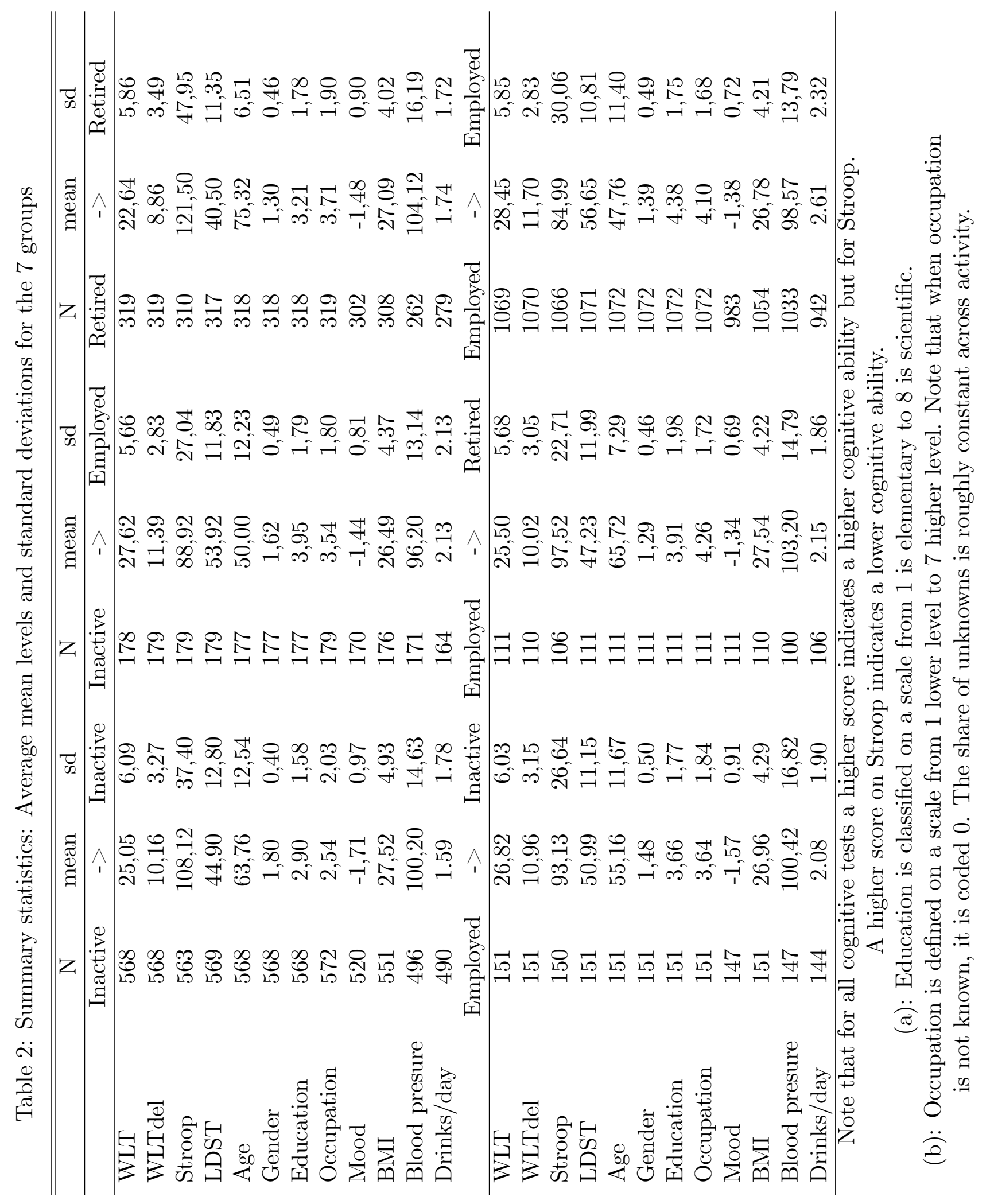




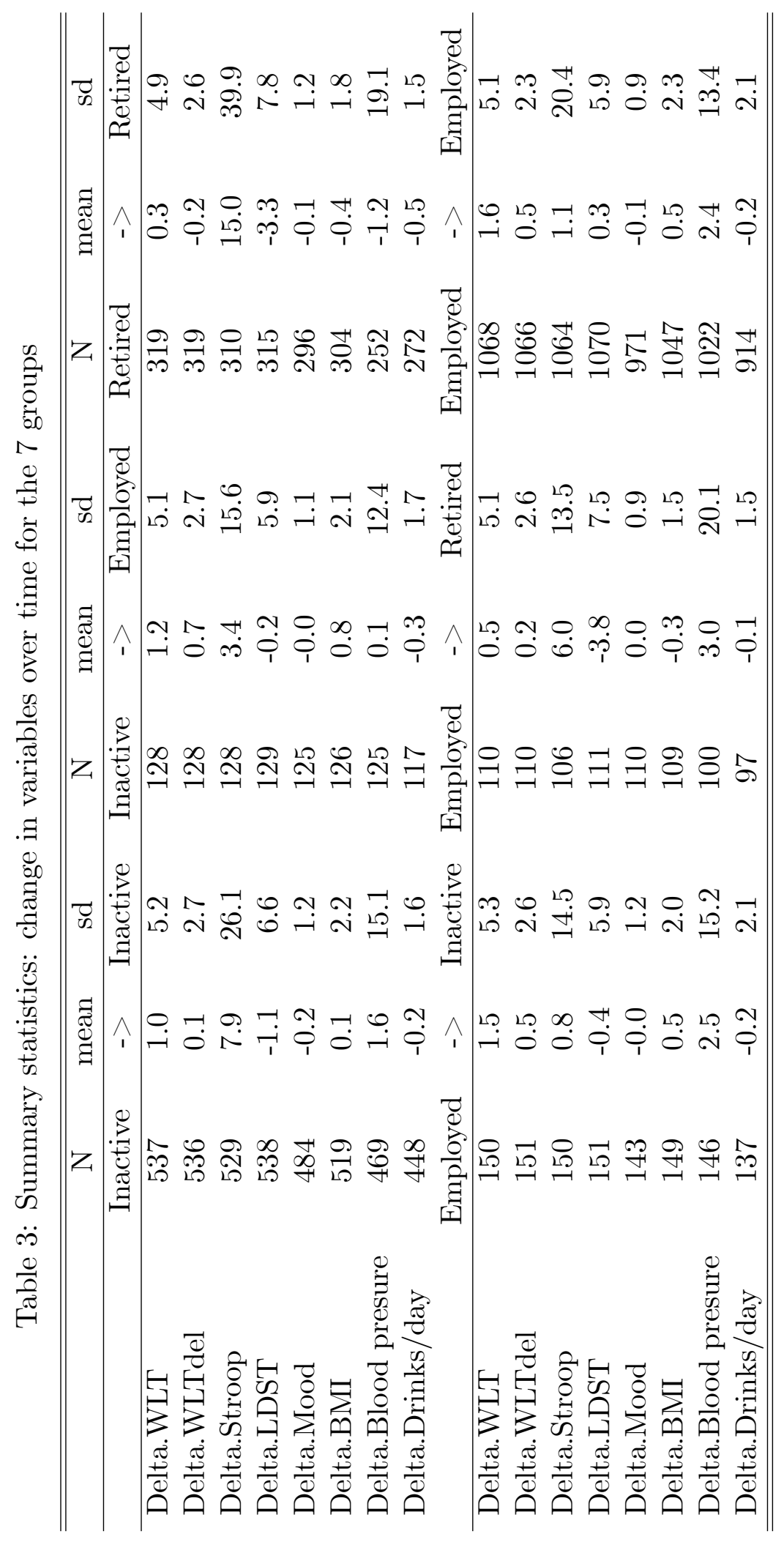


Table 4: OLS regression

\begin{tabular}{lcccc}
\hline \hline & WLT & WLT del & Stroop & LDST \\
Employed - > Employed & ref. & ref. & ref. & ref. \\
Retired -> Retired & 0.1630 & $0.3446^{*}$ & $-5.2899^{* * *}$ & 0.6679 \\
& $(0.360)$ & $(0.184)$ & $(1.928)$ & $(0.438)$ \\
Employed -> Retired & 0.1095 & 0.1202 & -3.7101 & -0.7708 \\
& $(0.462)$ & $(0.236)$ & $(2.479)$ & $(0.559)$ \\
Inactive -> Inactive & 0.0165 & 0.0186 & $-2.9331^{* *}$ & 0.0066 \\
& $(0.271)$ & $(0.139)$ & $(1.446)$ & $(0.330)$ \\
Inactive -> Employed & -0.0677 & 0.2008 & 0.5079 & 0.1303 \\
& $(0.414)$ & $(0.212)$ & $(2.187)$ & $(0.501)$ \\
Employed -> Inactive & 0.0739 & 0.0439 & -3.0510 & -0.1068 \\
& $(0.388)$ & $(0.198)$ & $(2.047)$ & $(0.470)$ \\
Period initial cognition & $-0.4530^{* * *}$ & $-0.4012^{* * *}$ & $-0.1040^{* * *}$ & $-0.1701^{* * *}$ \\
& $(0.018)$ & $(0.018)$ & $(0.025)$ & $(0.013)$ \\
Age & $0.1119^{* *}$ & $0.1263^{* * *}$ & $-1.6625^{* * *}$ & $0.2825^{* * *}$ \\
& $(0.052)$ & $(0.026)$ & $(0.277)$ & $(0.063)$ \\
Age square (/100) & $-0.1794^{* * *}$ & $-0.1557^{* * *}$ & $2.0272^{* * *}$ & $-0.4036^{* * *}$ \\
& $(0.044)$ & $(0.023)$ & $(0.240)$ & $(0.054)$ \\
Gender & $1.0239^{* * *}$ & $0.5438^{* * *}$ & $-2.1715^{* *}$ & $0.7042^{* * *}$ \\
& $(0.201)$ & $(0.103)$ & $(1.052)$ & $(0.239)$ \\
First period dummy & $1.0351^{* * *}$ & $0.4958^{* * *}$ & -1.0094 & $4.8764^{* * *}$ \\
& $(0.196)$ & $(0.097)$ & $(0.975)$ & $(0.231)$ \\
Constant & $9.5817^{* * *}$ & 1.2178 & $42.1681^{* * *}$ & 0.6338 \\
& $(1.592)$ & $(0.797)$ & $(8.536)$ & $(1.977)$ \\
Education dummies & Yes & Yes & Yes & Yes \\
Occupation dummies & Yes & Yes & Yes & Yes \\
Marital status dummies & Yes & Yes & Yes & Yes \\
\hline Observations & 2444 & 2442 & 2413 & 2443 \\
R squared & 0.282 & 0.242 & 0.148 & 0.354 \\
\hline
\end{tabular}

Standard errors in parentheses

$* \mathrm{p}<0.10{ }^{* *} \mathrm{p}<0.05{ }^{* * *} \mathrm{p}<0.01$ 
Table 5: Fixed-effects regressions

\begin{tabular}{lcccc}
\hline \hline & WLT & WLT-del & Stroop & LDST \\
\hline & & & & \\
Employed - > Employed & ref. & ref. & ref. & ref. \\
Retired -> Retired & 0.1788 & 0.2190 & $-8.9011^{*}$ & -1.3148 \\
& $(0.693)$ & $(0.412)$ & $(4.790)$ & $(1.306)$ \\
Employed -> Retired & 0.0247 & 0.3116 & $-5.6597^{*}$ & $-1.8771^{* * *}$ \\
& $(0.598)$ & $(0.253)$ & $(3.055)$ & $(0.721)$ \\
Inactive -> Inactive & 0.3716 & 0.3480 & -2.8811 & -0.6376 \\
& $(0.613)$ & $(0.309)$ & $(3.022)$ & $(0.850)$ \\
Inactive -> Employed & 0.2132 & 0.4089 & -2.2079 & 0.1659 \\
& $(0.550)$ & $(0.298)$ & $(3.408)$ & $(0.851)$ \\
Employed -> Inactive & -0.2391 & 0.2856 & -3.9168 & -0.1784 \\
& $(0.523)$ & $(0.234)$ & $(2.789)$ & $(0.697)$ \\
Period initial cognition & $-1.0879^{* * *}$ & $-0.9646^{* * *}$ & $-0.7556^{* * *}$ & $-0.7077^{* * *}$ \\
& $(0.049)$ & $(0.045)$ & $(0.217)$ & $(0.122)$ \\
Age & 0.0697 & $0.4143^{* *}$ & $-6.3888^{* * *}$ & $0.8689^{* *}$ \\
& $(0.294)$ & $(0.171)$ & $(1.532)$ & $(0.367)$ \\
Age square (/100) & $-0.2489^{* * *}$ & $-0.3415^{* * *}$ & $4.8770^{* * *}$ & $-1.0440^{* * *}$ \\
& $(0.094)$ & $(0.048)$ & $(0.675)$ & $(0.149)$ \\
First period dummy & -1.2189 & 0.5577 & -12.5176 & 2.8426 \\
& $(1.833)$ & $(0.991)$ & $(9.127)$ & $(2.022)$ \\
Observations & 2444 & 2442 & 2413 & 2443 \\
No. of individuals & 1359 & 1360 & 1341 & 1358 \\
\hline \hline
\end{tabular}

Standard errors in parentheses.

* $\mathrm{p}<0.10$ ** $\mathrm{p}<0.05$ *** $\mathrm{p}<0.01$. 
Table 6: Fixed-effects regressions: retirement and job level (white versus blue collar)

\begin{tabular}{lcccc}
\hline \hline & WLT & WLT-del & Stroop & LDST \\
\hline & & & & \\
Employed -> Employed & ref. & ref. & ref. & ref. \\
Retired - > Retired & 0.1418 & 0.1821 & $-9.0997^{*}$ & -1.3911 \\
& $(0.689)$ & $(0.408)$ & $(4.806)$ & $(1.322)$ \\
Employed -> Retired & -0.4212 & -0.1162 & -7.8041 & $-2.7710^{* * *}$ \\
& $(0.930)$ & $(0.390)$ & $(4.956)$ & $(1.065)$ \\
Employed -> Retired and white collar jobs & 0.7079 & 0.6683 & 3.3011 & 1.4054 \\
& $(1.000)$ & $(0.546)$ & $(5.593)$ & $(1.368)$ \\
Inactive -> Inactive & 0.3586 & 0.3360 & -2.9494 & -0.6655 \\
& $(0.611)$ & $(0.306)$ & $(3.020)$ & $(0.852)$ \\
Inactive -> Employed & 0.2070 & 0.4041 & -2.2388 & 0.1535 \\
& $(0.551)$ & $(0.298)$ & $(3.412)$ & $(0.856)$ \\
Employed -> Inactive & -0.2443 & 0.2809 & -3.9474 & -0.1923 \\
& $(0.524)$ & $(0.235)$ & $(2.774)$ & $(0.702)$ \\
Period initial cognition & $-1.0865^{* * *}$ & $-0.9618^{* * *}$ & $-0.7550^{* * *}$ & $-0.7010^{* * *}$ \\
& $(0.049)$ & $(0.045)$ & $(0.217)$ & $(0.123)$ \\
Age & 0.0712 & $0.4161^{* *}$ & $-6.3726^{* * *}$ & $0.8648^{* *}$ \\
& $(0.294)$ & $(0.171)$ & $(1.532)$ & $(0.372)$ \\
Age square (/100) & $-0.2477^{* * *}$ & $-0.3408^{* * *}$ & $4.8769^{* * *}$ & $-1.0391^{* * *}$ \\
& $(0.094)$ & $(0.048)$ & $(0.675)$ & $(0.151)$ \\
First period dummy & -1.1964 & 0.5768 & -12.4139 & 2.8679 \\
& $(1.835)$ & $(0.993)$ & $(9.146)$ & $(2.033)$ \\
Observations & 2444 & 2442 & 2413 & 2443 \\
No. of individuals & 1359 & 1360 & 1341 & 1358 \\
\hline \hline
\end{tabular}

Standard errors in parentheses .

$* \mathrm{p}<0.10 * * \mathrm{p}<0.05 * * * \mathrm{p}<0.01$. 
Table 7: Fixed-effects regressions: retirement and skills level (high-skilled versus low-skilled)

\begin{tabular}{lcccc}
\hline \hline & WLT & WLT-del & Stroop & LDST \\
\hline & & & & \\
Employed $->$ Employed & ref. & ref. & ref. & ref. \\
Retired $->$ Retired & 0.1813 & 0.1357 & $-8.6975^{*}$ & -1.5834 \\
& $(0.671)$ & $(0.409)$ & $(4.818)$ & $(1.310)$ \\
Employed $->$ Retired & 0.0377 & -0.1397 & -4.6312 & $-3.3565^{* * *}$ \\
& $(0.777)$ & $(0.339)$ & $(3.894)$ & $(0.983)$ \\
Employed -> Retired and high skills & -0.0247 & $0.8437^{*}$ & -1.8608 & $2.7947^{* *}$ \\
& $(0.968)$ & $(0.474)$ & $(4.954)$ & $(1.407)$ \\
Inactive -> Inactive & 0.3725 & 0.3203 & -2.8109 & -0.7320 \\
& $(0.611)$ & $(0.309)$ & $(3.077)$ & $(0.848)$ \\
Inactive -> Employed & 0.2136 & 0.3972 & -2.1755 & 0.1215 \\
& $(0.552)$ & $(0.300)$ & $(3.433)$ & $(0.855)$ \\
Employed -> Inactive & -0.2388 & 0.2746 & -3.8870 & -0.2194 \\
& $(0.526)$ & $(0.234)$ & $(2.790)$ & $(0.695)$ \\
Period initial cognition & $-1.0881^{* * *}$ & $-0.9594^{* * *}$ & $-0.7557^{* * *}$ & $-0.7026^{* * *}$ \\
Age & $(0.049)$ & $(0.046)$ & $(0.217)$ & $(0.122)$ \\
& 0.0699 & $0.4065^{* *}$ & $-6.3809^{* * *}$ & $0.8342^{* *}$ \\
Age square (/100) & $(0.294)$ & $(0.171)$ & $(1.536)$ & $(0.368)$ \\
& $-0.2490^{* * *}$ & $-0.3390^{* * *}$ & $4.8730^{* * *}$ & $-1.0331^{* * *}$ \\
First period dummy & $(0.094)$ & $(0.048)$ & $(0.678)$ & $(0.150)$ \\
& -1.2185 & 0.5319 & -12.4980 & 2.7156 \\
Observations & $(1.831)$ & $(0.991)$ & $(9.131)$ & $(2.025)$ \\
No. of individuals & 2444 & 2442 & 2413 & 2443 \\
\hline \hline
\end{tabular}

Standard errors in parentheses.

$* \mathrm{p}<0.10 * * \mathrm{p}<0.05 * * * \mathrm{p}<0.01$. 
Table 8: Fixed effects regressions: mood changes

\begin{tabular}{lcccc}
\hline \hline & WLT & WLT-del & Stroop & LDST \\
\hline & & & & \\
Employed - > Employed & ref. & ref. & ref. & ref. \\
Retired -> Retired & 0.8862 & 0.2641 & -8.0593 & -1.0586 \\
& $(0.871)$ & $(0.486)$ & $(6.657)$ & $(1.662)$ \\
Employed - > Retired & -0.0174 & 0.2144 & -5.0784 & $-1.7179^{*}$ \\
& $(0.608)$ & $(0.293)$ & $(3.721)$ & $(0.912)$ \\
Inactive -> Inactive & 0.8331 & 0.2450 & -2.0508 & -0.5661 \\
& $(0.762)$ & $(0.385)$ & $(5.000)$ & $(1.163)$ \\
Inactive -> Employed & 0.3084 & 0.2603 & -1.9136 & 0.4111 \\
& $(0.621)$ & $(0.303)$ & $(3.664)$ & $(0.951)$ \\
Employed -> Inactive & 0.2168 & 0.2074 & -4.1138 & 0.0812 \\
& $(0.545)$ & $(0.240)$ & $(3.500)$ & $(0.935)$ \\
Period initial cognition & $-1.0733^{* * *}$ & $-0.9740^{* * *}$ & $-0.8135^{* * *}$ & $-0.6940^{* * *}$ \\
& $(0.043)$ & $(0.051)$ & $(0.240)$ & $(0.127)$ \\
Age & -0.0111 & $0.5635^{* * *}$ & $-6.3602^{* * *}$ & $1.1386^{*}$ \\
Age square (/100) & $(0.274)$ & $(0.181)$ & $(2.351)$ & $(0.618)$ \\
& $-0.2174^{* *}$ & $-0.3558^{* * *}$ & $4.7499^{* * *}$ & $-0.9929^{* * *}$ \\
Change in mood & $(0.100)$ & $(0.056)$ & $(0.755)$ & $(0.128)$ \\
& 0.0791 & 0.0113 & -0.4494 & 0.1166 \\
First period dummy & $(0.076)$ & $(0.052)$ & $(0.592)$ & $(0.147)$ \\
& -1.4492 & 1.3138 & -12.5398 & 4.8214 \\
Observations & $(1.770)$ & $(1.006)$ & $(13.173)$ & $(3.364)$ \\
No. of individuals & 2056 & 2054 & 2038 & 2054 \\
\hline \hline
\end{tabular}

Standard errors in parentheses.

$* \mathrm{p}<0.10 * * \mathrm{p}<0.05 * * * \mathrm{p}<0.01$. 
Table 9: Fixed-effects regressions: BMI changes

\begin{tabular}{lcccc}
\hline \hline & WLT & WLT-del & Stroop & LDST \\
\hline \multirow{2}{*}{ Employed - $>$ Employed } & ref. & ref. & ref. & ref. \\
Retired - $>$ Retired & 0.1175 & 0.1022 & -8.1338 & -1.4575 \\
& $(0.779)$ & $(0.455)$ & $(5.676)$ & $(1.184)$ \\
Employed -> Retired & -0.0405 & 0.3056 & -5.5141 & $-1.8647^{* * *}$ \\
& $(0.420)$ & $(0.294)$ & $(3.596)$ & $(0.599)$ \\
Inactive -> Inactive & 0.4029 & 0.3601 & -3.1629 & -0.8426 \\
& $(0.615)$ & $(0.276)$ & $(3.021)$ & $(0.924)$ \\
Inactive -> Employed & 0.1847 & 0.4004 & -2.6138 & 0.0926 \\
& $(0.538)$ & $(0.297)$ & $(2.691)$ & $(0.785)$ \\
Employed -> Inactive & -0.1709 & 0.2858 & -4.2370 & -0.2440 \\
& $(0.553)$ & $(0.231)$ & $(2.651)$ & $(0.805)$ \\
Period initial cognition & $-1.0728^{* * *}$ & $-0.9573^{* * *}$ & $-0.7543^{* * *}$ & $-0.7420^{* * *}$ \\
& $(0.041)$ & $(0.040)$ & $(0.212)$ & $(0.105)$ \\
Age & -0.0893 & $0.3236^{* *}$ & $-6.3816^{* * *}$ & $0.9458^{* *}$ \\
Age square (/100) & $(0.342)$ & $(0.144)$ & $(1.764)$ & $(0.467)$ \\
& $-0.2351^{* *}$ & $-0.3223^{* * *}$ & $4.7911^{* * *}$ & $-1.0289^{* * *}$ \\
Change in BMI $(/ 100)$ & $(0.094)$ & $(0.042)$ & $(0.549)$ & $(0.145)$ \\
First period dummy & 4.4137 & $4.8084^{*}$ & 3.0630 & -5.5901 \\
Observations & $(5.018)$ & $(2.891)$ & $(2.688)$ & $(6.769)$ \\
No. of individuals & -2.1081 & 0.0928 & -13.1704 & 3.3046 \\
\hline \hline
\end{tabular}

Standard errors in parentheses.

$* \mathrm{p}<0.10$ ** $\mathrm{p}<0.05$ *** $\mathrm{p}<0.01$. 
Table 10: Fixed-effects regressions: blood presure changes

\begin{tabular}{lcccc}
\hline \hline & WLT & WLT-del & Stroop & LDST \\
\hline & & & & \\
Employed - > Employed & ref. & ref. & ref. & ref. \\
Retired - $>$ Retired & 0.2098 & 0.3172 & $-7.9699^{* *}$ & -1.4966 \\
& $(1.113)$ & $(0.499)$ & $(3.959)$ & $(1.235)$ \\
Employed - > Retired & 0.0239 & 0.4654 & $-6.8393^{* *}$ & $-1.6174^{*}$ \\
& $(0.616)$ & $(0.296)$ & $(2.727)$ & $(0.918)$ \\
Inactive -> Inactive & 0.4263 & 0.3742 & -1.2970 & -0.5821 \\
& $(0.581)$ & $(0.306)$ & $(2.578)$ & $(0.740)$ \\
Inactive -> Employed & 0.2690 & 0.3413 & -0.8216 & 0.1055 \\
& $(0.577)$ & $(0.360)$ & $(2.534)$ & $(0.731)$ \\
employed -> Inactive & -0.2401 & 0.1995 & -2.7198 & -0.1940 \\
& $(0.516)$ & $(0.268)$ & $(2.514)$ & $(0.775)$ \\
Period initial cognition & $-1.0591^{* * *}$ & $-0.9931^{* * *}$ & $-0.9837^{* * *}$ & $-0.8332^{* * *}$ \\
& $(0.045)$ & $(0.038)$ & $(0.152)$ & $(0.117)$ \\
Age & -0.0449 & $0.3761^{* * *}$ & $-4.9304^{* * *}$ & 0.5811 \\
& $(0.267)$ & $(0.131)$ & $(1.307)$ & $(0.426)$ \\
Age square (/100) & $-0.2345^{* * *}$ & $-0.3268^{* * *}$ & $4.0994^{* * *}$ & $-0.8636^{* * *}$ \\
& $(0.081)$ & $(0.054)$ & $(0.543)$ & $(0.124)$ \\
Change in blood pressure & 0.0069 & -0.0022 & $0.0607^{* *}$ & 0.0120 \\
& $(0.005)$ & $(0.003)$ & $(0.026)$ & $(0.010)$ \\
First period dummy & -1.7600 & 0.4274 & -8.1779 & 1.6986 \\
& $(1.619)$ & $(0.757)$ & $(8.146)$ & $(2.630)$ \\
Observations & 2223 & 2223 & 2204 & 2222 \\
No. of individuals & 1272 & 1273 & 1260 & 1271 \\
\hline \hline
\end{tabular}

Standard errors in parentheses.

$* \mathrm{p}<0.10 * * \mathrm{p}<0.05 * * * \mathrm{p}<0.01$. 
Table 11: Fixed-effects regressions: Alcohol consumption changes

\begin{tabular}{lcccc}
\hline \hline & WLT & WLT-del & Stroop & LDST \\
\hline & & & & \\
Employed - > Employed & ref. & ref. & ref. & ref. \\
Retired -> Retired & 0.2133 & -0.1477 & -4.9493 & 0.4706 \\
& $(1.273)$ & $(0.471)$ & $(6.084)$ & $(1.853)$ \\
Employed - > Retired & 0.1254 & 0.1656 & -2.7177 & -0.9776 \\
& $(0.619)$ & $(0.326)$ & $(3.981)$ & $(1.065)$ \\
Inactive -> Inactive & 0.4023 & 0.2641 & -1.0590 & 0.1556 \\
& $(0.851)$ & $(0.343)$ & $(4.215)$ & $(1.288)$ \\
Inactive -> Employed & 0.0936 & 0.2564 & -3.9300 & 1.6355 \\
& $(0.737)$ & $(0.290)$ & $(3.349)$ & $(1.079)$ \\
Employed -> Inactive & 0.0332 & 0.4081 & -3.4093 & 0.1021 \\
& $(0.530)$ & $(0.306)$ & $(3.265)$ & $(0.910)$ \\
Period initial cognition & $-1.1060^{* * *}$ & $-0.9519^{* *}$ & $-0.5991^{* * *}$ & $-0.6552^{* * *}$ \\
& $(0.061)$ & $(0.060)$ & $(0.177)$ & $(0.162)$ \\
Age & -0.0496 & $0.3909^{*}$ & $-5.0732^{* *}$ & $1.3945^{*}$ \\
Age square (/100) & $(0.368)$ & $(0.211)$ & $(2.210)$ & $(0.741)$ \\
& $-0.2576^{* *}$ & $-0.3247^{* * *}$ & $3.5362^{* * *}$ & $-1.2049^{* * *}$ \\
Change in drinks per day & $(0.103)$ & $(0.063)$ & $(0.697)$ & $(0.200)$ \\
& -0.0407 & 0.0286 & 0.2097 & 0.0229 \\
First period dummy & $(0.060)$ & $(0.031)$ & $(0.330)$ & $(0.122)$ \\
& -2.0069 & 0.4681 & -11.5842 & 5.3380 \\
Observations & $(2.216)$ & $(1.243)$ & $(12.438)$ & $(3.853)$ \\
No. of individuals & 1668 & 1667 & 1656 & 1667 \\
\hline \hline
\end{tabular}

Standard errors in parentheses.

$* \mathrm{p}<0.10 * * \mathrm{p}<0.05 * * * \mathrm{p}<0.01$. 
Table 12: Main coefficients of our preferred specifications for each test

\begin{tabular}{lcccc}
\hline \hline & WLT & WLT-del & Stroop & LDST \\
\hline & & & & \\
Employed $->$ Employed & ref. & ref. & ref. & ref. \\
Retired $->$ Retired & 0.1788 & 0.2190 & $-7.9699^{* *}$ & -1.5834 \\
Employed $->$ Retired & 0.0247 & 0.3116 & $-6.8393^{* *}$ & $-3.3565^{* * *}$ \\
Employed - $>$ Retired and high skills & & & & $2.7947^{* *}$ \\
Age & 0.0697 & $0.4143^{* *}$ & $-4.9304^{* * *}$ & $0.8342^{* *}$ \\
Age square (/100) & $-0.2489^{* * *}$ & $-0.3415^{* * *}$ & $4.0994^{* * *}$ & $-1.0331^{* * *}$ \\
Change in blood pressure & & & $0.0607^{* *}$ & \\
\hline \hline \multicolumn{4}{c}{$\mathrm{p}<0.10^{* *} \mathrm{p}<0.05$} & \\
\hline
\end{tabular}

